\title{
Guidelines and Quality
}

\section{Physician Characteristics and the Reported Effect of Evidence-Based Practice Guidelines}

\author{
Christine E. Sammer, Kristine Lykens, and Karan P. Singh
}

Objective. To explore characteristics that may contribute to the effect practice guidelines have on the practice of medicine.

Data Sources. From the third round of the Community Tracking Study, Physician Survey, 2000-2001.

Study Design. An ordinal logistic regression model was estimated to capture the full range of responses.

Principal Findings. Recent medical school graduates, women, minorities, ob-gyn specialists, physicians who use computers for information in their practices, and physicians in nonsolo practice types were significantly more likely to state practice guidelines had an effect on their practice.

Conclusions. Many barriers have prevented wide acceptance of practice guidelines among the medical community. Our findings suggest there will be positive results on guideline effects as recent graduates, women, and minorities enter the physician workforce.

Key Words. Evidence-based practice guidelines, physician characteristics

In 2002, health spending in the United States had climbed to 14.9 percent of the gross domestic product (GDP), advancing much faster than the rest of the U.S. economy and is projected to rise to $\$ 3.4$ trillion or 18.4 percent in 2013 (Centers for Medicare and Medicaid Services 2004; Levit et al. 2004). Concerns about the rapid growth in health expenditures are coupled with disturbing reports, such as those published by the Institute of Medicine (IOM), that attribute up to 98,000 unnecessary inpatient deaths per year due to medical error (IOM 2000) and suggest Americans are not receiving care that is based on the best scientific knowledge (IOM 2001). Although the IOM reports contributed significantly to increasing safety and quality awareness issues among health care providers, leaders are calling for a national commitment 
toward improving patient safety and quality of care (Leape and Berwick 2005).

A promising tool for reducing medical error, improving quality of care, and lowering health care cost is the development and use of evidencebased clinical practice guidelines (Cydulka et al. 2003; Maue et al. 2004; Timmermans and Mauck 2005). Hauck, Adler, and Mulla (2004) found that patients with community-acquired pneumonia (CAP) who were placed on a CAP clinical practice guideline had a decreased length of stay, lower odds of hospital mortality, and decreased total patient charges. Similarly, researchers found that patients with unstable angina pectoris and non-ST-segment elevation myocardial infarction who received care concordant with evidence-based practice guidelines had substantially improved long-term survival rates (Allen et al. 2004).

In 1999, the American College of Obstetricians and Gynecologists (ACOG) issued a practice guideline on vaginal birth after cesarean section (VBAC) and trial of labor (TOL). The guideline recommended that a physician be immediately available during TOL in the rare case of complications. Since the 1999 update of this clinical practice guideline, obstetrical providers in Utah have decreased use of TOL and more repeat cesarean sections are performed (Gochnour, Ratcliffe, and Stone 2005). Evidence-based clinical guidelines for acute respiratory tract infections, such as acute otitis media and acute sinusitis, have been associated with improving quality of care by assisting physicians to accurately diagnose these conditions, provide treatment rationales, and reduce the costs associated with inappropriate antibiotic prescriptions (McCracken 2001).

While the above examples illustrate compelling evidence for the use of clinical practice guidelines, the preponderance of literature examines reasons for poor implementation and adherence to practice guidelines. There is, additionally, limited research examining the characteristics of the physicians who use practice guidelines. The purpose of this paper is to identify and explore physician and practice characteristics that contribute to the effect physicians report practice guidelines have on their practice of medicine.

Address correspondence to Christine E. Sammer, M.P.H., R.N., 633 Cardinal Ridge, Burleson, TX 76028. Kristine Lykens, Ph.D., Department of Health Management and Policy, and Karan P. Singh, Ph.D., Department of Biostatistics, are with the University of North Texas Health Science Center, 3500 Camp Bowie Blvd., Fort Worth, TX 76107. 


\section{REVIEW OF LITERATURE}

Between 1992 and 1996, the Agency for Health Care Policy and Research (AHCPR), now the Agency for Healthcare Research and Quality (AHRQ), began publishing clinical practice guidelines for many different health diagnoses and problems (AHRQ 2004). AHCPR ended its clinical guidelines program in 1996 and a year later launched its initiative to promote evidencebased practice by establishing 12 Evidence-Based Practice Centers (AHRQ 2005). To disseminate the evidence, AHCPR partnered with the American Medical Association (AMA) and the American Association of Health Plans (AAHP) Foundation to sponsor the development of the National Guideline Clearinghouse $^{\mathrm{TM}}$ (NGC): a worldwide web-based database of evidence-based clinical practice guidelines (NGC 2005).

The literature supports many barriers to both the implementation of practice guidelines and compliance of use (Pathman et al. 1996; Cabana et al. 1999; Katz 1999; Halm et al. 2000; Ward et al. 2002). Barriers to adherence were generally focused on physician knowledge about clinical practice guidelines (Liu, Shilkret, and Finelli 1998), attitudes about guidelines such as loss of autonomy or "cookbook" medicine, and organizational factors including formats and accessibility (Harris et al. 2000). A relatively low adherence to guidelines usage was found among students, residents, and medical school faculty (Kogan, Reynolds, and Shea 2001). One study suggests barriers centered on concern over professional autonomy (Maue et al. 2004).

\section{METHODS}

\section{Participants}

The data for this analysis were obtained from the third round of the Community Tracking Study Physician Survey, 2000-2001 (CTS). The CTS is a longitudinal study conducted by the Center for Studying Health System Change (HSC) and funded by the Robert Wood Johnson Foundation to document changes and track the effects of the evolving U.S. health care system over time. The Physician Survey is a component of the CTS. Every 2 years since 1996, the Gallup Organization has conducted a telephone survey of more than 12,000 physicians from 60 communities that were selected using stratified sampling with a probability proportional to population size in order to provide a representative profile of the nation as a whole. The physicians must have spent at least 20 hours per week in direct patient care. Within each site, physicians were randomly selected from sampling frames stratified by 
primary care physician status. To increase the precision of national estimates, a supplemental sample, selected with stratified probability sampling, was included in the survey. Additionally, primary care physicians were over sampled in the site sample (Health and Medical Care Archive 2004).

\section{Dependent and Key Independent Variables}

The survey question most pertinent to this study and defined as the dependent variable was, "How large an effect does your use of formal, written practice guidelines such as those generated by physician organizations, insurance companies or HMOs, or government agencies have on your practice of medicine?" The key independent variables for this analysis were selected based upon prior research and the literature review. The first of these was the number of years since graduation from medical school. The thinking was that more recent graduates may have had greater exposure during medical school to the use of clinical practice guidelines as a method of practicing evidence-based medicine and additionally, may have had more exposure to information technology as methodologies for learning (Lee et al. 2004; Wolfe, Sharp, and Wang 2004; Choudhry, Fletcher, and Soumarai 2005).

Other independent variables were selected based on physician and practice characteristics that may contribute to the development of a clinical practice guideline user profile. Survey questions relevant to this analysis include: practice specialty type such as internal medicine, surgery, or obstetrics (Freed et al. 1998; Waldrop, Prejean, and Singleton 1998; Lee et al. 2004); board certification (Waldrop, Prejean, and Singleton 1998; Maue et al. 2004); the type of practice such as solo or two-man (Freed et al. 1998; Wolfe, Sharp, and Wang 2004); the use of computers to obtain information about treatment alternatives or recommended guidelines; and internet accessibility (Wolfe, Sharp, and Wang 2004).

\section{Statistical Analysis}

Preliminary analysis was conducted using the public-use data file. Once significant $p$-values were identified, the restricted data-use file was obtained through Inter-University Consortium for Political and Social Research (ICPSR), University of Michigan. The restricted-use version preserves physician anonymity while it contains more variables. It contains the sample design variables which allowed calculation of the corrected standard error estimates. The software used for the analyses was Intercooled Stata $8.1^{\mathbb{R}}$ (Stata Corporation 2003). 
The method of maximum likelihood was used in estimating the ordinal logit coefficients:

$$
\begin{aligned}
\text { Ologit }(Y)= & \beta_{0}+\beta_{1} \text { Gen }+\beta_{2} \text { Race }+\beta_{3} \text { YrGrad }+\beta_{4} \text { Spec }+\beta_{5} \text { BdCert } \\
& +\beta_{6} \text { PracType }+\beta_{7} \text { Computer }+\beta_{8} \text { Internet }
\end{aligned}
$$

where $Y$ : probability of the effect of practice guidelines on a physician's practice; Gen: gender as female, male; Race: white/Caucasian, Asian/Pacific Islander, African American/black, Native American/Alaska Native/other; Yr Grad: year of graduation from medical school; Spec: practice specialty; Bd Cert: board certification; Prac Type: type of practice; Computer: use of computer to obtain treatment information; Internet: Internet access at place where providing patient care.

The dependent variable, the effect of practice guidelines on practice, was measured using a Likert Scale and was ranked as $0=$ no effect to $5=$ a very large effect. Reference categories for the four categorical independent variables were: white/Caucasian; graduation from medical school before 1961; the practice specialty of internal medicine; and solo or group practice type of no more than two physicians.

\section{RESULTS}

\section{Descriptive Statistics}

The distributions of the dependent and independent variables are shown in Table 1 along with the proportion estimates and standard errors. Physicians reporting that the use of guidelines had a moderate effect on their practice were the most prevalent response at 33 percent. Slightly more than half (56 percent) of responding physicians stated that practice guidelines had a moderate to very large effect on their practice. The median for medical school graduation years was $1981-1985$ at 19.6 percent. About 39 percent of the respondents were practicing in primary care: internal medicine, family practice, and pediatrics. The largest group of respondents was physicians practicing in medical specialties such as cardiology, oncology, or pulmonology. Physicians practicing obstetrics and gynecology were the smallest population at about 6.3 percent. About 65 percent of the population practiced in a solo or group practice as opposed to practicing within an HMO or as a hospital employee. 
Table 1: Descriptive Statistics for Effect of Practice Guidelines on Practice and Independent Variables

\begin{tabular}{|c|c|c|c|}
\hline & Observations & $\begin{array}{c}\text { Estimated } \\
\text { Proportion (\%) }\end{array}$ & $S E$ \\
\hline \multicolumn{4}{|l|}{ Practice guidelines-ordinal } \\
\hline No effect & 1,047 & 9.35 & 0.0040 \\
\hline Very small effect & 1,396 & 11.37 & 0.0056 \\
\hline Small effect & 2,898 & 23.07 & 0.0055 \\
\hline Moderate effect & 4,238 & 33.43 & 0.0063 \\
\hline Large effect & 2,215 & 17.94 & 0.0056 \\
\hline Very large effect & 576 & 4.81 & 0.0029 \\
\hline \multicolumn{4}{|l|}{ Gender } \\
\hline Female & 3,275 & 23.55 & 0.0063 \\
\hline Male & 9,131 & 76.44 & 0.0063 \\
\hline \multicolumn{4}{|l|}{ Race } \\
\hline White/Caucasian & 9,774 & 80.23 & 0.0122 \\
\hline Asian/Pacific Islander & 1,541 & 12.33 & 0.0100 \\
\hline African American/black & 497 & 3.62 & 0.0027 \\
\hline Native American/Alaska Native/other & 465 & 3.80 & 0.0049 \\
\hline \multicolumn{4}{|l|}{ Graduation year } \\
\hline 1960 or earlier & 644 & 4.24 & 0.0028 \\
\hline $1961-1965$ & 657 & 5.34 & 0.0035 \\
\hline $1966-1970$ & 853 & 7.61 & 0.0033 \\
\hline $1971-1975$ & 1,349 & 12.11 & 0.0048 \\
\hline $1976-1980$ & 1,989 & 16.65 & 0.0051 \\
\hline 1981-1985 & 2,338 & 19.63 & 0.0054 \\
\hline $1986-1990$ & 2,230 & 18.47 & 0.0061 \\
\hline 1991-1995 & 2,037 & 14.32 & 0.0054 \\
\hline $1996-1998$ & 309 & 1.58 & 0.0010 \\
\hline \multicolumn{4}{|l|}{ Practice specialty } \\
\hline Internal medicine & 2,542 & 14.28 & 0.0058 \\
\hline Family/general practice & 3,273 & 16.98 & 0.0070 \\
\hline Pediatrics & 1,802 & 7.82 & 0.0025 \\
\hline Medical specialties & 2,402 & 29.35 & 0.0087 \\
\hline Surgical specialties & 1,407 & 18.83 & 0.0072 \\
\hline Psychiatry & 534 & 6.46 & 0.0035 \\
\hline Ob-gyn & 446 & 6.25 & 0.0036 \\
\hline \multicolumn{4}{|l|}{ Board certification } \\
\hline Board eligible only/neither & 1,526 & 11.30 & 0.0063 \\
\hline Board certified & 10,838 & 88.69 & 0.0063 \\
\hline \multicolumn{4}{|l|}{ Practice type } \\
\hline Solo/2 physician & 4,292 & 35.20 & 0.0116 \\
\hline Group $\geq 3$ physicians & 3,593 & 30.22 & 0.0102 \\
\hline $\mathrm{HMO}-\mathrm{P}$ & 551 & 3.78 & 0.0037 \\
\hline Medical school & 970 & 8.43 & 0.0063 \\
\hline Hospital-based & 1,660 & 11.99 & 0.0073 \\
\hline Other & 1,340 & 10.35 & 0.0053 \\
\hline
\end{tabular}


Table 1. Continued

\begin{tabular}{lccc}
\hline & & Estimated & \\
& Observations & Proportion (\%) & $S E$ \\
\hline Computer use & & & \\
No & 5,922 & 47.08 & 0.0085 \\
Yes & 6,469 & 52.91 & 0.0085 \\
Internet access & & & \\
No & 3,049 & 22.87 & 0.0079 \\
Yes & 9,323 & 77.12 & 0.0079 \\
\hline
\end{tabular}

SE, standard error.

\section{Ordinal Logistic Regression}

The binary logistic regression methods are applied when there is a categorical response of the simplest possible form-dichotomous. These methods require collapsing data when there are more than two possible values, thus, causing loss in information. A variety of methods have been developed for determining categorical responses that have more than two possible values. The best known and most highly developed are methods for ordinal response variables, called ordinary logistic regression methods. In this project, initially, binary logistic regression models were estimated to identify factors correlated to the effect of practice guidelines. Then an ordinal logistic regression model was estimated where the full range of the response categories was included. The ordinal model was found to be a better fit to the data and is included in the paper. The fitted model assumes proportional odds for the independent variables for each of the effects variable categories.

Table 2 shows the results of this model. The $F$ statistic of $27(p<.001)$ indicates that the predictive value of this model is significant. Females are significantly more likely to indicate perceived effects of practice guidelines than males $(\beta=-.222, p<.01)$. Asians and physicians from the Pacific Islands indicated a strong positive effect of practice guideline $(\beta=.624, p<.001)$ and African-American physicians indicated a significant effect of practice guidelines $(\beta=.421, p<.01)$. Physicians graduating in 1996 or after are correlated with a strong effect of practice guidelines $(\beta=.513, p<.01)$. Three practice specialty categories showed significant findings. Ob-gyn physicians showed a strong effect of practice guidelines $(\beta=.426, p<.01)$ while medical and surgical specialists were less likely to show an effect of guidelines in this ordinal model. All practice types had significant positive logit coefficients when compared with the reference group of solo or two physician practices 
Table 2: Survey Ordinal Logistic Regression Analysis for Effect of Practice Guidelines on Practice

\begin{tabular}{|c|c|c|}
\hline Practice Guideline & Coefficient Estimate ${ }^{\dagger}$ & $S E$ \\
\hline \multicolumn{3}{|l|}{ Gender } \\
\hline Male & $-0.222^{* *}$ & 0.065 \\
\hline \multicolumn{3}{|l|}{ Race } \\
\hline Asian/Pacific Islander & $0.624^{* * * *}$ & 0.071 \\
\hline African American/black & $0.421^{* *}$ & 0.122 \\
\hline Native American/Alaskan/other & 0.199 & 0.154 \\
\hline \multicolumn{3}{|l|}{ Graduation year } \\
\hline $1961-1965$ & 0.009 & 0.191 \\
\hline $1966-1970$ & 0.090 & 0.175 \\
\hline $1971-1975$ & 0.050 & 0.153 \\
\hline $1976-1980$ & 0.075 & 0.142 \\
\hline $1981-1985$ & 0.047 & 0.137 \\
\hline $1986-1990$ & 0.178 & 0.142 \\
\hline $1991-1995$ & 0.286 & 0.146 \\
\hline $1996-$ & $0.513^{* * *}$ & 0.175 \\
\hline \multicolumn{3}{|l|}{ Practice specialty } \\
\hline Family/general practice & -0.050 & 0.068 \\
\hline Pediatrics & 0.045 & 0.074 \\
\hline Medical specialties & $-0.168^{* *}$ & 0.064 \\
\hline Surgical specialties & $-0.357^{* * * *}$ & 0.099 \\
\hline Psychiatry & -0.056 & 0.112 \\
\hline Ob-gyn & $0.426^{* *}$ & 0.133 \\
\hline Board certification & -0.121 & 0.069 \\
\hline \multicolumn{3}{|l|}{ Practice type } \\
\hline Group $\geq 3$ & $0.223^{* *}$ & 0.068 \\
\hline $\mathrm{HMO}^{-}$ & $0.614^{* * * *}$ & 0.145 \\
\hline Medical school & $0.275^{*}$ & 0.107 \\
\hline Hospital-based & $0.156^{*}$ & 0.071 \\
\hline Other & $0.291^{* * * * *}$ & 0.081 \\
\hline Computer use & $0.411^{* * * *}$ & 0.050 \\
\hline Internet access & -0.039 & 0.058 \\
\hline
\end{tabular}

The coefficients represent the change in the effect of practice guidelines on the practice of medicine.

$* p<.05$.

$* * p<.01$.

$* * * * 0.001$.

Number of observations 12,159 .

$F(26,2,705) 27$.

$p$-value $<.0001$.

groups. Physicians who use a computer to obtain information about alternative treatments or recommended guidelines showed a significant effect of practice guidelines $(\beta=.411, p<.001)$. 
Table 3: Thresholds for the Effect of Practice Guidelines on Practice as Compared with No Effect

\begin{tabular}{lccc}
\hline Practice Guideline Effect & Coefficient Estimate & $S E$ & Wald t-test \\
\hline Threshold 1 & -2.167 & 0.155 & $-13.96^{*}$ \\
$\quad \begin{array}{l}\text { 1: Very small effect } \\
\text { Threshold 2 } \\
\quad \text { 2: Small effect }\end{array}$ & -1.205 & 0.150 & $-8.01^{*}$ \\
$\begin{array}{l}\text { Threshold 3 } \\
\quad \text { 3. Moderate effect }\end{array}$ & -0.065 & 0.146 & $-0.44^{* * *}$ \\
$\begin{array}{l}\text { Threshold 4 } \\
\text { 4. Large effect }\end{array}$ & 1.469 & 0.149 & $9.80^{*}$ \\
$\begin{array}{l}\text { Threshold 5 } \\
\text { 5. Very large effect }\end{array}$ & 3.272 & 0.157 & $20.76^{*}$ \\
\hline
\end{tabular}

$* p<.001$.

$* * p>.05$.

Threshold coefficients for each of the categories of effect of practice guidelines are shown in Table 3. All of these, except the "moderate effect" category, were significantly different from the "no effect" reference category with the coefficients of small to very small having negative logit coefficients (lower probabilities) and the categories of large to very large effect having positive (higher probabilities) than the "no effect" category.

\section{DISCUSSION}

No graduation year from before 1960 and up to 1995 was significant for effect of guidelines. This may be explained by the fact that practice guideline development and implementation did not begin until the early 1990s. Our results suggest, as the proportion of practicing physicians graduating after 1996 increases, so will the effect of practice guidelines. Because more women have been graduating from medical school in recent years and our results showed that practice guidelines had a greater effect on their practice than on their male colleagues, our findings imply this will also have a positive effect on the use of practice guidelines.

Compared with white/Caucasian physicians, Asian and African-American physicians showed significant associations with increased effect of practice guidelines. We do not know why this finding was significant. Perhaps one reason may be that their minority status encourages them to be more attentive to using established medical practices. 
A surprising finding was that access to the Internet did not contribute significantly to the model. This may be because before 1998, agencies such as the National Guideline Clearinghouse ${ }^{\mathrm{TM}}$ did not post their practice guidelines on the Internet. However, computer use to obtain information about treatment and recommended guidelines did contribute significantly to the model. This may be because of increasing third party payer and federal and state requirements for electronic communication of administrative data and patient health information. Thus, the accessibility of computers in the work environment may lead to increased use of computers for information gathering.

Several factors, however, were found to have no significant associations on the effect of practice guidelines. In fact, physicians practicing in a medical or surgical specialty were less likely to indicate that practice guidelines had an effect on their practice. This is despite the fact that the literature supports that many medical specialty groups have developed and published practice guidelines specific to their specialty. Medical specialty groups may benefit from further educational efforts to their membership regarding practice guidelines.

No specialty practice area except ob-gyn positively contributed to the likelihood of the effect of guidelines. This specialty is often closely scrutinized in our litigious environment, which may lead to attentiveness to published guidelines.

We found it interesting that board-certified physicians are less likely to state practice guidelines had an effect on their practice than nonboard-certified physicians. This finding may suggest board certified physicians are more secure in their knowledge base and therefore, would be less influenced by guidelines to assist them in their decisions about appropriate health care for specific clinical circumstances.

The findings suggest further research to identify other factors affecting the effect of practice guidelines. More research related to behavior, attitudes and perceptions related to loss of autonomy would be a valuable addition to the body of knowledge. In addition, we believe the succeeding rounds of the CTS Physician Survey will support our findings because many of the characteristics correlated to effects of practice guidelines have a temporal aspect.

This study does have limitations. The sample of physicians selected for the survey was not a simple random sample of the population of all physicians. The sampling frame was physicians practicing in designated cities, ranging from very large to small. Therefore, the findings should not be generalized to all physicians, particularly not to those in rural practice. Interpretation of the findings should consider that physicians were asked for perceptions of the 
impact of practice guidelines on their own practice. No direct measures of this impact were available.

\section{IMPLICATIONS FOR POLICY AND PRACTICE}

Because studies have shown positive correlations between the use of practice guidelines and improved quality and patient safety and decreased costs (McCracken 2001; Hauck, Adler, and Mulla 2004; Gochnour, Ratcliffe, and Stone 2005), our findings suggest that there will be positive results on health care as recent graduates, women, and minorities continue to enter the physician workforce. Additionally, as computer usage becomes more prevalent in clinical practice, the influence of guidelines on physician practice will have a positive effect on health care in the United States.

Policy initiatives such as the promotion or requirement for information technology in health care should reinforce the tendencies found in this study. Furthermore, the introduction and requirements for medical students to learn and use computer technologies from the outset of their clinical training should also increase the effects of guidelines on practice. Additionally, the inclusion of women and minorities in the medical profession reinforces these policy and practice developments.

\section{ACKNOWLEDGMENTS}

The authors appreciate the reviewer's thoughtful and constructive comments. The authors also appreciate the suggestions made by Romana HasnainWynia, Ph.D., Senior Associate Editor and Harold S. Luft, Ph.D., Co-Editorin-Chief.

\section{REFERENCES}

Agency for Healthcare Research and Quality (AHRQ). 2004 "Clinical Practice Guidelines Online" [accessed on October 26, 2004]. Available at http://www.ahrq. gov/clinic/cpgonline.htm

—. 2005. "Evidence-Based Practice Centers" [accessed on May 23, 2005]. Available at http://www.ahrq.gov/clinic/epc

Allen, L. A., C. J. O’Donnell, R. P. Giugliano, C. A. Camargo Jr, and D. M. LloydJones. 2004. "Care Concordant with Guidelines Predicts Decreased Long-Term 
Mortality in Patients with Unstable Angina Pectoris and Non-ST-Elevation Myocardial Infarction." American Journal of Cardiology 93 (10): 1218-22.

Cabana, M. D., C. S. Rand, N. R. Powe, B. W. Wu, M. H. Wilson, P. C. Abboud, and H. R. Rubin. 1999. "Why Don't Physicians Follow Clinical Practice Guidelines?" Journal of the American Medical Association 282 (15): 1458-65.

Centers for Medicare and Medicaid Services. 2004. "National Health Care Expenditures" [accessed on May 4, 2005]. Available at http://www.cms.hhs.gov/ publications/overview-medicare-medicaid/default2.asp

Choudhry, N. K., R. H. Fletcher, and S. B. Soumerai. 2005. "Systematic Review: The Relationship between Clinical Experience and Quality of Health Care." Annals of Internal Medicine 142 (4): 260-73.

Cydulka, R. K., B. H. Rowe, S. Clark, C. L. Emerman, and C. A. Camargo. 2003. "Emergency Department Management of Acute Exacerbations of Chronic Obstructive Pulmonary Disease in the Elderly: The Multicenter Airway Research Collaboration." Journal of the American Geriatric Society 51: 908-16.

Freed, G. L., D. E. Pathman, T. R. Konrad, V. A. Freeman, and S. J. Clark. 1998. "Adopting Immunization Recommendations: A New Dissemination Model." Maternal and Child Health Journal 2 (4): 231-9.

Gochnour, G., S. Ratcliffe, and M. B. Stone. 2005. "The UTAH VBAC Study." Maternal and Child Health Journal 9 (2): 181-8.

Halm, E. A., S. J. Atlas, L. H. Borowsky, T. I. Benzer, J. P. Metlay, Y. C. Chang, and D. E. Singer. 2000. "Understanding Physician Adherence with a Pneumonia Practice Guideline: Effects of Patient, System, and Physician Factors." Archives of Internal Medicine 160: 98-104.

Harris, J. S., K. Mueller, P. Low, B. Peplowski, and J. Koziol-McLain. 2000. "Suggested Improvements in Practice Guidelines: Market Research to Support Clinical Quality Improvement.” Journal of Occupational and Environmental Medicine 42 (4): 377-84.

Hauck, L. D., L. M. Adler, and Z. D. Mulla. 2004. "Clinical Pathway Care Improves Outcomes among Patients Hospitalized for Community-Acquired Pneumonia.” American Journal of Epidemiology 14 (9): 669-75.

Health and Medical Care Archive. [Accessed on October 17, 2004.] Available at http://www.icpsr.umich.edu/HMCA

Institute of Medicine. 2000. To Err Is Human: Building a Safer Health System, edited by L. T. Kohn, J. M. Corrigan, and M. S. Donaldson. Washington, DC: National Academy Press.

- 2001. Crossing the Quality Chasm: A New Health System for the 21st Century. Washington, DC: National Academy Press.

Katz, D. A. 1999. "Barriers between Guidelines and Improved Patient Care: An Analysis of AHCPR's Unstable Angina Clinical Practice Guideline." Health Services Research 34 (1, part 2): 377-89.

Kogan, J. R., E. E. Reynolds, and J. A. Shea. 2001. "Resident and Faculty Adherence to Common Guidelines." Academic Medicine 76 (10): S27-9.

Leape, L. L., and D. M. Berwick. 2005. "Five Years after To Err Is Human: What Have We Learned?" Journal of the American Medical Association 293 (19): 2384-90. 
Lee, K. C., J. A. Finkelstein, I. L. Miroshnik, D. Rusinak, J. M. Santoli, S. M. Lett, and T. A. Lieu. 2004. "Pediatricians' Self-Reported Clinical Practices and Adherence to National Immunization Guidelines: The Introduction of Pneumococcal Conjugate Vaccine." Archives of Pediatrics and Adolescent Medicine 158 (7): 695-701.

Levit, K., C. Smith, C. Cowan, A. Sensenig, and A. Catlin. 2004. "Health Spending Rebound Continues in 2002." Health Affairs 23 (1): 147-59.

Liu, Z., K. L. Shilkret, and L. Finelli. 1998. "Initial Drug Regimens for the Treatment of Tuberculosis: Evaluation of Physician Prescribing Practices in New Jersey, 1994 to 1995." Chest 113 (6): 1446-51.

Maue, S. K., R. Segal, C. L. Kimberlin, and E. E. Lipowski. 2004. "Predicting Physician Guideline Compliance: An Assessment of Motivators and Perceived Barriers." American Journal of Managed Care 10 (6): 383-91.

McCracken, G. H. Jr. 2001. "Clinical Practice Guidelines for the Diagnosis and Treatment of Respiratory Tract Infections." American Journal of Managed Care 7 (6 suppl): S183-91.

National Guideline Clearinghouse ${ }^{\mathrm{TM}}$. 2005. "What Is the National Guideline Clearinghouse $^{\mathrm{TM}}$ ?" [accessed on July 24, 2005]. Available at http://www.ahrq.gov/ clinic/ngcfact.htm

Pathman, D. E., T. R. Konrad, G. L. Freed, V. A. Freeman, and G. G. Koch. 1996. "The Awareness-to-Adherence Model of the Steps to Clinical Guideline Compliance: The Case of Pediatric Vaccine Recommendations." Medical Care 34 (9): 873-89.

Stata Corporation. 2003. Inter-Cooled Stata 8.1 for Windows ${ }^{\circledR}$. College Station, Texas: Stata Corporation.

Timmermans, S., and A. Mauck. 2005. "The Promises and Pitfalls of Evidence-Based Medicine." Health Affairs 24 (1): 18-28.

Waldrop, R. D., C. Prejean, and R. Singleton. 1998. "Overuse of Parenteral Antibiotics for Wound Care in an Urban Emergency Department." American Journal of Emergency Medicine 16 (4): 343-5.

Ward, M. M., T. E. Vaughn, T. Uden-Holman, B. N. Doebbeling, W. R. Clarke, and R. F. Woolson. 2002. "Physician Knowledge, Attitudes and Practices Regarding a Widely Implemented Guideline." Journal of Evaluation in Clinical Practice 8 (2): 155-62.

Wolfe, R. M., L. K. Sharp, and R. M. Wang. 2004. "Family Physicians Opinions and Attitudes to Three Clinical Practice Guidelines." Journal of the American Board of Family Practice 17 (2): 150-57. 